\title{
Reforma administrativa e marco legal das organizações sociais no Brasil: as dúvidas dos juristas sobre o modelo das organizações sociais ${ }^{1}$
}

\author{
Paulo Eduardo Garrido Modesto
}

Revista do

Serviço

Público

Ano 48

Número 2

Mai-Ago 1997

\section{Reforma administrativa e reforma na mentalidade administrativa: o papel dos juristas}

A reforma administrativa do aparelho do Estado no Brasil tem, na introdução e alteração de normas, no âmbito da Constituição da República e das leis do país, uma de suas etapas necessárias. Porém, a eficácia da reforma administrativa está condicionada ainda a uma concomitante reforma na mentalidade dos agentes públicos. É indispensável para a efetiva implementação da reforma pretendida que os agentes administrativos superem o tradicional vezo burocrático que vem convertendo a Administração, nas palavras de Dromi, numa cara "máquina de impedir", fiel ao que o mesmo autor batizou como o "código do fracasso", que dispõe: "artigo primeiro: não pode; artigo segundo: em caso de dúvida, abstenha-se; artigo terceiro, se é urgente, espere; artigo quarto, sempre é mais prudente não fazer nada" (1995:35).

A reforma administrativa, iniciada no Brasil, guarda semelhança com outras reformas do Estado, ocorridas em várias partes do mundo, conforme se pode observar nas experiências relatadas por Palazzo, Sésin e Lembeye, no livro La Transformación del Estado (1992).

De fato, são aspectos comuns às diversas reformas contemporâneas do Estado:

a) aplicação de novas técnicas de coordenação de serviços e atividades entre esferas políticas diversas (consórcios intergovernamentais, acordos-programas, convênios de delegação ou descentralização);

b) estímulo à privatização de serviços econômicos competitivos sustentáveis em regime de mercado;

Assessor especial do ministro da Administração Federal e Reforma do Estado do Brasil e professor de direito da Universidade Federal da Bahia 
c) transferência de funções do poder central para entes intermediários e locais;

d) ampliação dos controles de produtividade e de economicidade, vale dizer, do resultado do trabalho administrativo (controles de eficiência);

e) fortalecimento da autonomia das entidades personalizadas da administração indireta;

f) incentivo à gestão direta pela comunidade de serviços sociais e assistenciais, fora do aparato burocrático do Estado, porém com apoio direto dele e com sua assistência permanente (organizações não-governamentais, associações de utilidade pública, escolas comunitárias);

g) estímulo ao pessoal administrativo no desenvolvimento de atividades-fim, com a concomitante diminuição ou terceirização de atividades-meio, acompanhada de valorização das carreiras exclusivas de Estado, inclusive mediante adequação do padrão remuneratório ao mercado de trabalho;

h) capacitação de pessoal dirigente e criação de carreiras específicas para altos gestores;

i) elaboração do conceito de planejamento estratégico e fortalecimento dos setores administrativos responsáveis pela formulação de políticas públicas;

j) consolidação e simplificação de procedimentos e processos no interior da administração;

1) estímulo ao desenvolvimento de habilitações gerenciais flexíveis do pessoal administrativo, fator a ser considerado no próprio recrutamento, mediante a ampliação do grau de generalidade das atribuições contempladas nos cargos públicos;

m) definição de novas formas de responsabilização dos agentes públicos pela gestão administrativa;

n) adoção de programas de desregulamentação ou de simplificação da legislação (consolidação e codificação legislativa);

o) ampliação dos mecanismos de participação popular na atividade administrativa e de controle social da administração pública.

Essas tarefas, apenas mencionadas para formação de um quadro simplificado de referência, permitem também inferir os objetivos práticos que servem de base finalista aos projetos mais conhecidos de Reforma do Estado:

a) objetivo econômico: diminuir o "déficit" público, ampliar a poupança pública e a capacidade financeira do Estado concentrar recursos em áreas em que é indispensável a sua intervenção direta;

b) objetivo social: aumentar a eficiência dos serviços sociais oferecidos ou financiados pelo Estado, atendendo melhor o cidadão a um custo menor, zelando pela interiorização na prestação dos serviços e ampliação do seu acesso aos mais carentes;

c) objetivo político: ampliar a participação da cidadania na gestão da coisa pública; estimular a ação social comunitária; desenvolver esforços 
para a coordenação efetiva das pessoas políticas no implemento de serviços sociais de forma associada;

d) objetivo gerencial: aumentar a eficácia e efetividade do núcleo estratégico do Estado, que edita leis, recolhe tributos e define as políticas públicas; permitir a adequação de procedimentos e controles formais e substituí-los, gradualmente; porém, de forma sistemática, por mecanismos de controle de resultados.

É manifesto que este amplo quadro de tarefas e objetivos somente é alcançável com a ação cooperativa dos envolvidos no processo de implementação das reformas, em especial, com a colaboração dos juristas, responsáveis imediatos pela interpretação do direito reformado.

Nesse sentido, recorde-se Pontes de Miranda:

"Fez-se cânon da Crítica moderna ser-lhe indispensável a simpatia.

Interpretar a lei não é só criticá-la: é inserir-se nela, e fazê-la viver. A exigência, portanto, cresce de ponto, em se tratando de Constituição. Com a antipatia não se interpreta, - ataca-se; porque interpretar é se pôr do lado que se interpreta, numa intimidade maior do que permite qualquer anteposição, qualquer contraste, por mais consentinte, mais simpático, que seja, do intérprete e do texto. Portanto, a própria simpatia não basta. É preciso compenetrar-se do pensamento que esponta nas regras jurídicas escritas; e, penetrando-se nelas, dar-lhes a expansão doutrinária e prática, que é o comentário jurídico. Só assim se executa o programa do jurista, ainda que, de quando em vez, se lhe juntem conceitos e correções de lege ferenda” (1987: 5) (Grifo nosso).

Com efeito, parece possível interpretar e refletir sobre o que representa o programa das organizações sociais para a redefinição do modo de intervenção do Estado no âmbito social apenas se adotarmos uma atitude de abertura, de ânimo desarmado, negação da mentalidade burocrática antes referida, que desconfia do novo e o renega de plano, adulterando o seu sentido próprio a partir de antigos esquemas conceituais.

$\mathrm{Na}$ verdade, a atitude aposta a de abertura, a atitude de bloqueio “a priori”, é impensável e inaceitável entre juristas, que são profissionais do diálogo, acostumados a tratar cotidianamente com novas demandas político-sociais.

O saber dos juristas é um saber de protagonistas; pois, mediante o discurso dos juristas são estabelecidas decisões ou condições para a tomada de decisões jurídicas. Enquanto a maior parte das ciências opera com um objeto dado, que o cientista pressupõe como uma unidade estável, o objeto do jurista é um objeto lingüístico, socialmente condicionado, que se elabora e se apresenta ao domínio público mediante a 
decisão interpretativa, amplamente influenciada pelo instrumental elaborado pela ciência do direito. Esta é a razão de se dizer, não sem algum exagero, que o objeto do saber do jurista não é algo dado ao seu conhecimento, mas o resultado do seu labor.

Essa interferência da doutrina jurídica na definição e avaliação do direito vigente aumenta a responsabilidade social da dogmática jurídica e dos próprios juristas individualmente. Da dogmática jurídica, pois, cabelhe estabelecer os limites do conhecimento jurídico válido (as condições de validação científica do labor dos juristas), restringindo o arbitrário interpretativo, estabelecendo métodos de trabalho que neutralizem ao máximo as puras inclinações subjetivas ou pessoais. Dos juristas, pois, como agentes sociais que monopolizam o discurso técnico sobre as normas da coletividade, têm condições de antecipar as conseqüências negativas e positivas da aplicação das normas jurídicas aprovadas, propor novas pautas de solução de conflitos, bem como capacidade de enquadrar de forma argumentativa os novos conflitos no interior do direito já existente, enfraquecendo ou eliminando temporariamente conflitos. Sobre tema da função social da dogmática jurídica, ver Ferraz Jr. (1994: 280-1; 1980:149 e segs).

O desafio de pensar juridicamente as organizações sociais faz crescer de importância a vocação de protagonista dos juristas, pois estes são convidados a co-participar da constituição desta nova "figura jurídica", sem reservas e sem temor de pensar o novo.

\section{As dúvidas dos juristas sobre as organizações sociais}

São basicamente duas as dúvidas levantadas pelos juristas durante o processo de discussão do modelo de organizações sociais, apresentado pelo Ministério da Administração Federal e Reforma do Estado do Brasil. A primeira, de caráter geral, diz respeito à própria identificação do que sejam as organizações sociais e o papel que cumpririam perante a administração pública. Em termos técnicos, ao fim e ao cabo, esta primeira indagação diz também sobre a possibilidade e natureza jurídica das organizações sociais. Discute-se aqui sobre se as organizações sociais desenvolveriam atividades de serviço público ou atividades privadas, sobre se constituiriam formas de privatização de entes públicos, bem como sobre quais os traços diferenciais que as apartariam das tradicionais entidades privadas de utilidade pública. Na segunda questão, de caráter especial, indaga-se sobre se será cabível a exigência de realização de processo licitatório para a cessão de bens e recursos públicos às entidades reconhecidas como organizações sociais, o regime jurídico do apoio que lhes emprestará o Poder Público, bem como sobre o que as distinguirá das entidades privadas que prestam serviços à Administração Pública mediante contratos de terceirização. 
Não existe ainda uma definição legal das organizações sociais no plano federal no Brasil. O projeto elaborado pelo Poder Executivo Federal, em vias de ser enviado ao Congresso Nacional, conquanto não tenha ainda sido formalmente apresentado, foi copiado e tornado lei em diversos estados da Federação. (v.g., Pará, Lei no 5.980/96; Bahia, Lei no 7.027/97). É importante saber que o projeto federal, ao longo do tempo, sofreu reformulações, de conteúdo e forma, que lhe alteraram profundamente a compostura, sem embargo de uma continuidade firme nos propósitos básicos. A última versão do projeto, apresentado em anexo a este trabalho, servirá de fundamento para as definições e afirmações adiante expostas.

Uma definição operacional das organizações sociais pode ser formulada nos termos seguintes. As organizações sociais são pessoas jurídicas de direito privado, sem fins lucrativos, voltadas para atividades de relevante valor social, que independem de concessão ou permissão do Poder Público, criadas por iniciativa de particulares segundo modelo previsto em lei, reconhecidas, fiscalizadas e fomentadas pelo Estado.

Em sentido abrangente, as organizações sociais representam uma forma de parceria do Estado com as instituições privadas de fins públicos (perspectiva ex parte principe) ou, sob outro ângulo, uma forma de participação popular na gestão administrativa (perspectiva ex parte populi).

No aspecto da parceria, as organizações sociais definem-se como instituições do terceiro setor (pessoas privadas de fins públicos, sem fins lucrativos, constituídas voluntariamente por particulares, auxiliares do Estado na persecução de atividades de relevante interesse coletivo), pois possuem o mesmo substrato material e formal das tradicionais pessoas jurídicas privadas de utilidade pública. Não são um novo tipo de pessoa jurídica privada nem entidades criadas por lei e encartadas na estrutura da administração pública. São pessoas jurídicas estruturadas, sob a forma de fundação privada ou associação sem fins lucrativos. Ser organização social, por isso, não significa apresentar uma estrutura jurídica inovadora, mas possuir um título jurídico especial, conferido pelo Poder Público em vista do atendimento de requisitos gerais de constituição e funcionamento previstos expressamente em lei. Estes requisitos são de adesão voluntária por parte das entidades privadas e estão dirigidos a assegurar a persecução efetiva e as garantias necessárias a uma relação de confiança e parceria entre o ente privado e o Poder Público.

A denominação organização social é um enunciado elíptico. Denominam-se sinteticamente organizações sociais as entidades privadas, fundações ou associações sem fins lucrativos, que usufruem do título de organização social. 
Essa qualidade jurídica conferida pelo Poder Público faz incidir sobre as instituições reconhecidas um plexo de disposições jurídicas especiais, que asseguram vantagens e sujeições incomuns para as tradicionais pessoas jurídicas qualificadas pelo título de utilidade pública. Em qualquer dos dois títulos referidos, porém, dá-se um plus à personalidade jurídica das entidades privadas, que passam a gozar de benefícios especiais não-extensíveis às demais pessoas jurídicas privadas (benefícios tributários e vantagens administrativas diversas). A todo rigor, portanto, nenhuma entidade é constituída como organização social. Ser organização social não se pode traduzir em uma qualidade inata, mas em uma qualidade adquirida, resultado de um ato formal de reconhecimento do Poder Público, facultativo e eventual, semelhante em muitos aspectos à qualificação deferida às instituições privadas sem fins lucrativos quando recebem o título de utilidade pública.

De fato, as organizações sociais são juridicamente entidades bastante semelhantes às tradicionais entidades privadas declaradas de utilidade pública, mas com elas não se identificam de modo completo. São traços comuns às duas entidades:

a) a iniciativa privada voluntária na sua criação e na sua constituição;

b) a existência de limites gerais à livre constituição e funcionamento dos órgãos de direção ou gerência como requisito para o exercício de ato posterior de reconhecimento ou qualificação;

c) a afetação a uma finalidade de interesse público ou socialmente relevante;

d) o recebimento de favores especiais, subsídios, isenções e contribuições do Estado;

e) a submissão a uma vigilância especial e a limitações de ordem administrativa que vão além do simples poder de polícia exercido sobre as demais pessoas privadas;

f) sujeição ao controle do Tribunal de Contas;

g) a necessidade de reconhecimento formal por parte do Estado, segundo um procedimento especial regulado em lei;

h) a destinação legal do patrimônio social a outra entidade de mesma natureza, em caso de extinção da entidade, não sendo permitido seja o patrimônio repartido entre os membros da instituição;

i) a submissão ao regime jurídico das pessoas de direito privado, com derrogações de direito público.

As organizações sociais, no entanto, apresentam também características especiais que as distinguem de modo parcial das tradicionais entidades privadas declaradas de utilidade pública. Em resumo, os traços diferenciais básicos são os seguintes:

a) os seus estatutos devem prever e adotar determinado modelo de composição para os seus órgãos de deliberação superior, inclusive 
prevendo a participação necessária de representantes do Estado, como requisito para permitir o ato posterior de qualificação pelo Poder Público;

b) o trespasse de bens e recursos públicos nelas está condicionado à assinatura de contratos de gestão com os órgãos competentes da administração pública federal;

c) o estatuto deve prever, também como um requisito da qualificação, sujeição da entidade à publicação anual no Diário Oficial da União do relatório de execução do acordo ou contrato de gestão (relatório gerencial das atividades desenvolvidas, apoiadas pelo Poder Público, e não apenas do relatório formal da contabilidade da entidade);

d) o estatuto deve prever, como requisito de qualificação, regras rígidas de reforma das finalidades sociais, bem como regras para a definição impessoal das regras a serem adotadas para a remuneração do pessoal da entidade e para o sistema de compras;

e) o estatuto ainda deve prever que a entidade estará sujeita a controle externo de resultados, periódico e "a posteriori", realizado por comissão de avaliação composta por especialistas de notória qualificação, especialmente destinado à verificação do cumprimento do contrato ou acordo de gestão firmado com o Poder Público;

f) as entidades poderão utilizar bens materiais e recursos humanos de entidades extintas do Estado, desde que a extinção tenha sido realizada por lei específica;

g) as entidades poderão também absorver atividades e contratos de entidade extintas, também quando autorizados por lei, bem como os seus símbolos designativos, desde que estes sejam seguidos obrigatoriamente do símbolo OS.

As diferenças e semelhanças entre as duas entidades são manifestas, mas indicam também ser possível identificá-las como entidades da mesma espécie, ainda que inconfundíveis. As organizações sociais são entidades de utilidade pública qualificadas por maiores restrições $e$ maior vigilância do Estado, no mesmo passo em que podem receber deste maiores benefícios e vantagens incomuns - embora não vedadas — às atuais entidades privadas de utilidade pública.

Algumas vantagens têm surpreendido os juristas, em especial a possibilidade prevista de haver absorção, pelas entidades qualificadas, de atividade e recursos de entidades estatais extintas por lei específica (ex $v i$ art. 37, XIX, da Constituição federal e do princípio da "paridade das formas"). Os bens de entidade extinta de ordinário revertem ao patrimônio da União, mas poderá haver permissão de uso para as organizações sociais que recebam autorização legal especial para assumirem atividades e compromissos do ente extinto. Ainda que a vantagem dependa de fato duplamente eventual (a extinção do ente público e a falta de definição na lei específica de outro destino para o patrimônio ou os bens da entidade 
encerrada, por ex., doação a Estados e Municípios), alguns juristas têm retirado da hipótese duas conclusões contrapostas ou contraditórias. Para alguns, trata-se de benefício revelador de que as organizações sociais não passarão de entidades estatais de administração indireta, encobertas sob a forma de pessoas privadas, mas na verdade veículos expressivos do Poder do Estado. Para outros, trata-se de demonstração de que as organizações sociais nada mais são do que uma nova forma de privatização, de dissolução do patrimônio público, em detrimento do interesse coletivo. O equívoco é duplo.

As organizações sociais, no modelo proposto, não serão autarquias veladas, nem titularizarão qualquer espécie de prerrogativa de direito público. Não gozarão de prerrogativas processuais especiais ou prerrogativas de autoridade. Não estarão sujeitas a supervisão ou tutela da administração pública direta ou indireta, respondendo apenas pela execução e regular aplicação dos recursos e bens públicos vinculados ao acordo ou contrato de gestão que firmarem com o Poder Público. Não serão instituídas por lei nem custeadas na sua integridade, de modo necessário, pelo Poder Público. Serão entidades privadas reconhecidas pelo Estado, à semelhança das atuais entidades de utilidade pública, devendo sua constituição jurídica à iniciativa voluntária de indivíduos. Não serão criaturas do Estado, nem sucessoras necessárias de entidades públicas extintas. Podem ser reconhecidas ou qualificadas como tais, independentemente da extinção de qualquer ente público existente. Quando forem autorizadas a assumirem, porém, atividades e prédios anteriormente ocupados por entidades extintas — benefício incomum hoje, mas não inconcebível para as próprias instituições tradicionais de utilidade pública —, mediante autorização legal específica, nem por isso deixarão de ser ou agir como pessoas privadas para transformarem-se em entes do Estado. Exemplo: suponha-se que uma Santa Casa de Misericórdia, instituição tradicionalíssima no Brasil de prestação de serviços de saúde e assistência social, aceite adaptar os seus estatutos ao modelo de constituição e demais obrigações previstas na lei, recebendo, posteriormente, o título de organização social, bem como a permissão de uso de prédio público ocioso anteriormente utilizado por hospital público, recursos públicos de apoio ou fomento, etc., desde que assumisse metas e compromissos de realizar atividades especificadas num acordo de gestão com o Poder Público. Essa entidade estaria, por isso, transformada em mais uma autarquia, uma fundação pública, uma repartição burocrática? Não, é certo. Do mesmo modo que permaneceria com a mesma personalidade jurídica uma universidade privada que, mesmo sem receber benefício algum de qualquer ente público extinto, atendesse aos requisitos da lei das organizações sociais, recebesse o título, assumindo compromissos de atuação com o poder público com objetivo de obter uma inversão mais intensa ou regular de recursos públicos de fomento para atividades comunitárias que pretenda ampliar. O Poder Público teria novos 
instrumentos para afiançar a boa utilização dos recursos investidos na atividade social ampliada e a entidade privada novos meios de planejamento a longo prazo das atividades que realiza.

As organizações sociais tampouco serão formas de privatização de entes públicos. Privatização pressupõe uma transferência de domínio, isto é, o trespasse de um ente do domínio estatal para o domínio particular empresarial, uma transação de natureza econômica e uma retração do Poder Público em termos de inversão de recursos e em termos quantitativos de pessoal. No modelo das organizações sociais, esses pressupostos não comparecem. Primeiro, porque o ato de qualificação de uma entidade como organização social independe de qualquer extinção prévia ou posterior de ente público. Segundo, porque quando as entidades qualificadas recebem prédios ou bens públicos como forma de apoio ou fomento por parte do Estado não há transferência de domínio, mas simples permissão de uso, continuando os bens a integrar o patrimônio da União. Terceiro, porque os contratos ou acordos de gestão que o Estado firmar com as entidades qualificadas não terão nem poderão ter finalidade ou natureza econômica, convergindo para uma finalidade de natureza social e de interesse público, cuja realização obrigatoriamente não pode objetivar o lucro ou qualquer outro proveito de natureza empresarial. A relação entre as organizações sociais e o Poder Público deve ter fundamento numa ética da solidariedade e numa ética do serviço. Quarto, porque o Estado não apresentará qualquer retração financeira, patrimonial ou de pessoal quando vier a qualificar ou permitir o uso de bens públicos por organizações sociais. A instituição qualificada, pelo contrário, demandará do Poder Público apoios e subvenções, tendo em vista o objetivo comum de persecução do interesse público. O modelo das organizações sociais, assim, realiza-se como estratégia em tudo oposta a de privatização, assumindo claramente uma opção de recusa à aplicação da lógica do mercado nas atividades de natureza social.

Tanto as organizações sociais quanto as atuais entidades de utilidade pública podem ser descritas como entes privados que colaboram com a Administração, mas que com ela não se identificam. Fala-se então em “descentralização por colaboração" (ANDRÉA FERREIRA, 1972:62) e em “descentralização social da administração" (MorEIRA NETO: 1989:98). Com estas expressões enfatizam os autores que essas entidades, conquanto privadas, possuem atuação "pública", "pública não-estatal”, "paraestatal”, "de interesse coletivo", "de realização do bem comum", que as aproximam, como parceiras privilegiadas, da administração pública.

Moreira Neto (1989: 98), já ao lume da Constituição brasileira de outubro de 1988, averbava:

"A descentralização social consiste em retirar do Estado a execução direta ou indireta de atividades de relevância coletiva 
que possam ser cometidas a unidades sociais já existentes, personalizadas ou não, como a família, o bairro, as agremiações desportivas, as associações profissionais, as igrejas, os clubes de serviço, as organizações comunitárias, etc., mediante simples incremento de autoridade e institucionalização jurídica adequada, de modo que possam promover, elas próprias, sua execução.

Essas unidades, também denominadas de entidades de cooperação, receberiam tais atribuições a partir de leis específicas e de atos administrativos concretos de reconhecimento, modalidade assemelhada à autorização e à permissão. Tratam-se de institutos ainda em desenvolvimento, mas que têm seu lugar garantido numa sociedade dinâmica e participativa". (Grifo nosso)

As organizações sociais, em verdade, podem ser percebidas pela Administração Pública como entidades privadas de cooperação, mas divergimos, com respeito e temor, de qualificá-las como forma de "descentralização". Nisto modificamos entendimento que também sustentamos no passado. A rigor, tecnicamente, fala-se em descentralização ou, mais precisamente, descentralização por colaboração quando o particular atua em atividades reservadas ou exclusivas do Poder Públi$c o$, sob o regime jurídico público. No domínio destas atividades, algumas podem ter sua execução delegada ao particular, sob as formas de concessão, permissão ou autorização de serviço (art. 175 da Constituição da República). No entanto, nas áreas ou atividades em que a atuação do Poder Público é expressa pelo simples "poder de polícia", uma vez que a Constituição da República reconhece a ação autônoma e em nome próprio dos particulares (ensino, saúde, pesquisa, desporto, pesquisa, etc.), parece descabido falar em delegação, descentralização ou transferência de execução de atividade. Não faz sentido falar-se em transferência de funções, doutrina Cassagne, nas atividades exercidas por particulares de iure proprio (1994:24).

As organização sociais, por todo o exposto, são organizações especialmente vocacionadas a travar parcerias com o Poder Público para atividades de interesse coletivo. A idéia de parceria, como se sabe, é uma idéia-força deste final de século. Fala-se em parceria atualmente em quase todos os ramos do direito. No direito internacional, as nações fortalecem laços estratégicos, econômicos e políticos, firmando parcerias regionais (Mercosul, Nafta, União Européia); no direito do trabalho, mecanismos de participação dos empregados nos lucros da empresa dão os primeiros passos no que se tem denominado parceria entre empregadores e empregados; no direito administrativo, renascem as concessões e permissões de serviço público como formas de parceria dos particulares com o Estado em áreas estratégicas de natureza econômica. Fora da esfera 
da ordem econômica, inclusive no âmbito dos direitos sociais, a parceria entre particulares e o Estado até o momento ressente-se de melhor institucionalização e aperfeiçoamento.

A insuficiente institucionalização da matéria tem como um dos seus principais fundamentos o caráter excessivamente lacônico da legislação básica sobre declaração de utilidade pública no Brasil. A legislação vigente no plano federal, por exemplo, trata indiferentemente todos os diversos tipos de associações e fundações sem fins lucrativos. Não diferencia o que denominamos entidades de favorecimento mútuo ou de fins mútuos (dirigidas a proporcionar benefícios a um círculo restrito ou limitado de sócios, inclusive mediante a cobrança de contribuições em dinheiro, facultativas ou compulsórias) e as entidades de fins comunitários (dirigidas a oferecer utilidades concretas ou benefícios especiais à comunidade de um modo geral, sem considerar vínculos jurídicos especiais, quase sempre de forma gratuita). A ambas confere o título, autorizando um tratamento mais benéfico por parte da Administração (renúncia fiscal, previsão de subvenções sociais, contratação direta, etc.), deixando ainda de prever qualquer forma mais efetiva de controle de resultados. (PEREIRA JúNIOR, 1973:90; OLIVEIRA, 1996:64-8). Este caráter indiferenciado da referência às entidades e a debilidade do sistema de controle tem estimulado abusos importantes e fomentado a desconfiança em atividades e relações de parceria em que este é um valor fundamental (ex. escândalo do Orçamento). Consideramos, porém, que o modelo das organizações sociais é uma das respostas possíveis a este impasse, pois apenas estimula a criação de entidades de fins comunitários, auto e heterolimitadas para a persecução objetiva de fins coletivos (exigência de regras impessoais para compras e plano de salários; existência de colegiado superior composto por fundadores, personalidades da comunidade e representantes do poder público; previsão de auditorias gerenciais e controle de resultados; fomento público condicionado à assinatura de contrato ou acordo de gestão com o Poder Público, definidor de metas e tarefas a cumprir; responsabilização direta dos dirigentes pela regular utilização dos recursos públicos vinculados ao acordo de gestão, entre outras garantias atualmente não exigidas para o deferimento do título de utilidade pública para as entidades privadas sem fins lucrativos).

De outra parte, vale insistir que essas formas de cooperação privada e parceria com o Poder Público, de importância crescente na sociedade complexa dos nossos dias, estão diretamente vinculadas à idéia de participação popular na esfera pública. São "fórmulas cooperativas de participación", na expressão sintética de Enterría e Fernandes (1989:078 e seg.). Estes autores, dissertando sobre o tema, afirmam ser este modo de atuação participativa mais intenso do que os demais conhecidos, uma vez que "no se refiere a actuaciones aisladas 
sino a conductas permanentes institucionalizadas", realizadas "mediante la creación por los cidadanos de organizaciones especiales", vocacionadas a "fines de interés general" (1989:86). Trata-se de modalidade de participação popular consentânea com o princípio fundamental da cidadania (art. $1^{\circ}$, II, da Constituição da República), fundamento do Estado Democrático de Direito. Entre os dispositivos constitucionais que a contemplam diretamente, podemos indicar os seguintes:

“Art. 199. A assistência à saúde é livre à iniciativa privada.

$\S 1 .^{\circ}$ As instituições privadas poderão participar de forma complementar do sistema único de saúde, segundo diretrizes deste, mediante contrato de direito público ou convênio, tendo preferência as entidades filantrópicas e as sem fins lucrativos.

Art. 204. As ações governamentais na área da assistência social serão realizadas com recursos do orçamento da seguridade social, previstos no art. 195, além de outras fontes, e organizadas com base nas seguintes diretrizes:

I - descentralização político-administrativa, cabendo a coordenação e as normas gerais à esfera federal e a coordenação e a execução dos respectivos programas às esferas estadual e municipal, bem como a entidades beneficentes e de assistência social;

Art. 205. A educação, direito de todos e dever do Estado e da família, será promovida e incentivada com a colaboração da sociedade, visando ao pleno desenvolvimento da pessoa, seu preparo para o exercício da cidadania e sua qualificação para o trabalho.

Art. 213. Os recursos públicos serão destinados às escolas públicas, podendo ser dirigidos a escolas comunitárias, confessionais ou filantrópicas, definidas em lei, que:

I - comprovem finalidade não lucrativa e apliquem seus excedentes financeiros em educação;

II - assegurem a destinação de seu patrimônio a outra escola comunitária, filantrópica ou confessional, ou ao poder público, no caso de encerramento de suas atividades.

Art. 216

$\S 1 .^{\circ} \mathrm{O}$ poder público, com a colaboração da comunidade, promoverá e protegerá o patrimônio cultural brasileiro, por meio de inventários, registros, vigilância, tombamento e desapropriação, e de outras formas de acautelamento e preservação. (...)

Art. 227. É dever da família, da sociedade e do Estado assegurar à criança e ao adolescente, com absoluta prioridade, o direito 
à vida, à saúde, à alimentação, à educação, ao lazer, à profissionalização, à cultura, à dignidade, ao respeito, à liberdade e à convivência familiar e comunitária, além de colocá-los a salvo de toda forma de negligência, discriminação, exploração, violência, crueldade e opressão.

$\S 1 .^{\circ} \mathrm{O}$ Estado promoverá programas de assistência integral à saúde da criança e do adolescente, admitida a participação de entidades não-governamentais e obedecendo aos seguintes preceitos:

Outras disposições constitucionais referem-se de forma reflexa a esta mesma forma de colaboração de entidades particulares com a administração pública, a saber:

1) igrejas (arts. 19, I - colaboração, de interesse público, com a União, Estados, Distrito Federal e Municípios; art. 226, § 2, celebração do casamento religioso com efeito civil; art. 213, escolas confessionais);

2) instituições privadas de educação (art. 150, VI, c - imunidade tributária, desde que sem fins lucrativos);

3) instituições de assistência social beneficentes ou filantrópicas (art. 150, VI, c - imunidade tributária, desde que sem fins lucrativos; art. $195, \S 7^{\circ}$ - isenção de contribuição para a seguridade social);

4) terceiros e pessoas físicas e jurídicas de direito privado na área da saúde (arts. 197 - declaração de relevância pública das ações e serviços de saúde pelos mesmos executados);

5) organizações representativas da população (art. 30, X - cooperação no planejamento municipal; art. 58, II - participação de audiências públicas de comissões do Poder Legislativo);

6) serviços notariais e de registros (arts. 236, e $\S \S-s e r v i c ̧ o s$ privados mas por delegação do poder público);

7) entidades privadas em geral - art. 74, II (cabe ao sistema de controle interno integrado dos Poderes Legislativo, Executivo e Judiciário a comprovação da legalidade e avaliação dos resultados, também quanto à eficácia e eficiência, da aplicação de recursos públicos por entidades de direito privado).

Essas disposições revelam a extensão que tomou a cidadania participativa e a parceria público-privado na Constituição de 1988, assinalando ainda algumas das diversas modalidades de estímulo, utilizadas pelo Estado para atrair e premiar a colaboração de entidades privadas em atividades de acentuada relevância social:

a) imunidade tributária (art.150, VI, “c”, art. 195, $\$ 7^{\circ}$ e art.240);

b) trespasse de recursos públicos (art. 204, I; art. 213; art. $216, \S 3^{\circ}$, art.61,ADCT); 
c) preferência na contratação e recebimento de recursos (art. 199, $\S 1^{\circ}$, in fine).

A mesma orientação foi seguida pela legislação ordinária. A Lei n 8.666, de 21.06.93, por exemplo, reza no seu art. 24, "verbis":

Art. 24. É dispensável a licitação:

XIII- na contratação de instituição nacional sem fins lucrativos, incumbida regimental ou estatutariamente da pesquisa, do ensino ou do desenvolvimento institucional, científico ou tecnológico, desde que a pretensa contratada detenha inquestionável reputação ético-profissional;

XX- na contratação de associação de portadores de deficiência física, sem fins lucrativos e de comprovada idoneidade, por órgãos ou entidades da Administração Pública, para a prestação de serviços ou fornecimento de mão-de-obra, desde que o preço contratado seja compatível com o praticado no mercado.

A Lei Orgânica da Assistência Social - LOAS, Lei no 8.742, de 7.12.1993, dispõe sobre amplo mecanismo de cooperação dos particulares nos projetos prioritários de assistência social, reconhecendo expressamente no art. 26 três categorias participantes do sistema de cooperação: organismos governamentais, não-governamentais e da sociedade civil, "verbis":

Art. 26. O incentivo a projetos de enfrentamento da pobreza assentar-se-á em mecanismos de articulação e de participação de diferentes áreas governamentais e em sistema de cooperação entre organismos governamentais, não-governamentais e da sociedade civil.

Nesta nova ordem de idéias, tem-se que o Estado não deve nem tem condições de monopolizar a prestação direta, executiva, dos serviços públicos e dos serviços de assistência social de interesse coletivo. Estes podem ser geridos ou executados por outros sujeitos, públicos ou privados, inclusive públicos não-estatais, como associações ou consórcios de usuários, fundações e organizações não-governamentais sem fins lucrativos, sempre sob a fiscalização e supervisão imediata do Estado. Poderão ainda ser operados em regime de co-gestão, mediante a formação de consórcios intergovernamentais ou entre o poder público e pessoas jurídicas privadas. O Estado deve permanecer prestando-os diretamente quando não encontre na comunidade interessados que os efetivem de modo mais eficiente ou econômico ou quando razões ponderáveis de justiça social ou segurança pública determinem sua intervenção. Não prover diretamente não quer dizer tornar-se irresponsável perante essas necessidades sociais básicas. Não se trata de reduzir o 
Estado a mero ente regulador. O Estado apenas regulador é o Estado Mínimo, utopia conservadora insustentável ante as desigualdades das sociedades atuais. Não é este o Estado que se espera que resulte das reformas em curso em todo o mundo. O Estado deve ser regulador e promotor dos serviços sociais básicos e econômicos estratégicos. Precisa garantir a prestação de serviços de saúde de forma universal, mas não deter o domínio de todos os hospitais necessários; precisa assegurar o oferecimento de ensino de qualidade aos cidadãos, mas não estatizar todo o ensino. Os serviços sociais devem ser fortemente financiados pelo Estado, assegurados de forma imparcial pelo Estado, mas não necessariamente realizados pelo aparato do Estado. Neste contexto, crescem de importância os denominados entes "públicos não-estatais". (BRESSER Pereira, 1996: 285-87; 1997: 25-31; CunILl Grau, 1996: 126-137)

A palavra público, é certo, vem utilizada nesta expressão no sentido teleológico de toda atividade que alcança, afeta ou interessa a todos ou à maioria e não no sentido de um determinado regime jurídico. É público, ainda neste sentido material, a atividade ou o produto da atividade que é tornada acessível à maioria. Por oposição, privado é o que é destinado a poucos ou a um só, reservado a poucos, inacessível à maioria. (Bоввіо, 1987:13-31).

Na doutrina internacional do direito administrativo, vem se acentuando o emprego da palavra público nesta acepção — sem embargo de sua utilização técnica para referir o regime jurídico próprio do Estado e de seus delegados. Exemplo disto vemos em Dromi (1991:6):

"La administración es pública. No es solamente ejecutiva ni únicamente estatal, sino que es más que estatal. La Administración Pública es el género y la estatal una de las especies. Lo público no está solamente en manos del Estado. El Estado no es el único dueno y soberano de lo público, pues en la 'administración de lo público' deben participar, también, los cuerpos intermedios que comprenden a las corporaciones profesionales, los sindicatos, los consorcios públicos, las cooperativas públicas, los concesionarios de servicios públicos, las universidades privadas y otros modelos organizativos que crea la sociedad, en función del pluralismo social, para que detenten la defensa del interés de algunos que, junto al de los demás, es el interés de todos". ${ }^{2}$

Para este autor, a atuação de particulares em atividades de fins públicos deve ser estimulada intensamente na denominada "democracia participativa", uma vez ultrapassada a fase da democracia meramente representativa: 
"No se puede pretender que el Estado monopolice la atención de todas las necesidades colectivas. El crecimiento cuantitativo y cualitativo de las mismas, propio de la complejidad vital moderna, requiere una participación más activa de los cuerpos intermedios en el quehacer de la Administración Pública. (...) La democracia, como forma civilizada de vivir, aspira a la realización plena del hombre en libertad, para ello exige una 'participación integral', no sólo política ni política simplemente electoralista, sino también administrativa, económica y social. El hombre debe ser 'partícipe' de la gestión pública en sus distintos niveles institucionales". (1995:82). ${ }^{3}$

Não há, portanto, impedimento constitucional algum à assunção por particulares de tarefas e missões de interesse social em colaboração com a administração pública. Desde de que cumpridos requisitos de salvaguarda do interesse público, mais intensos e onerosos quanto mais ampla for a transferência de encargos e recursos, a cooperação é lícita e até mesmo estimulada pela Constituição da República.

Sem embargo do exposto, essa forma de atuação direta dos particulares, ou de entes privados, na gestão direta de serviços ofertados ao público, alguns até prestados concomitantemente pelo Estado, não nos deve levar a confundir duas situações jurídicas completamente distintas, a saber, a dos serviços privados de interesse público e a dos serviços públicos.

\subsubsection{Serviços privados de interesse público e serviços públicos}

Não basta prestar serviços ao público, inclusive sem objetivo de lucro, para ingressar na categoria jurídica de serviço público.

Bandeira de Mello (1995: 418) ensina com precisão:

"Dentre o total de atividades ou serviços suscetíveis de serem desenvolvidos em uma sociedade, alguns são públicos e outros privados.

Para separar uns dos outros, identificando aqueles que o Estado pode colocar debaixo do regime de direito público (serviços públi$\cos$ ), temos que nos valer de duas ordens de indicações contidas no Texto Constitucional.

A primeira delas é a de que certas atividades a própria Carta Constitucional definiu como serviços públicos: alguns deles em todo e qualquer caso e outros deles apenas quando prestados pelo Estado; pois ou (a) entregou-os expressamente à responsabilidade privativa do Estado, ora devendo ser prestados exclusivamente por ele ou por empresa sob controle acionário estatal, 
caso dos arrolados no art. 21, X e XI, ora cabendo sua prestação quer ao Estado, quer a terceiro, mediante autorização, concessão ou permissão, caso dos previstos no inciso XII do mesmo art. 21; ou então (b) previu-os como serviços incluíveis na categoria de serviços públicos, quando prestados pelo Estado. É o caso dos serviços: (I) de saúde, conforme previsão do art. 196 ("dever do Estado"), os quais, entretanto, também estão entregues à livre iniciativa, como estabelece o art. 199 ("A assistência à saúde é livre à iniciativa privada"), sendo de todo modo qualificados como “serviços de relevância pública” (art. 197, primeira parte), e (II) de educação, ex vi do art. 205 ("dever do Estado"), inobstante também eles estejam entregues à livre iniciativa, a teor do art. 209 ("O ensino é livre à iniciativa privada, atendidas as seguintes condições: I - cumprimento das normas gerais da educação nacional; II - e autorização e avaliação de qualidade pelo Poder Público").

Estes últimos, de conseguinte, não serão serviços públicos quando desempenhados por particulares, uma vez que a Carta Magna não limitou a prestação deles ao Estado ou a quem lhe faça as vezes. Segue-se que o Estado jamais poderia pretender outorgálos em concessão a alguém, sob pena de ferir os direitos de prestálos que assistem às demais pessoas que preencham os requisitos legais necessários à comprovação de suas habilitações”. (Grifos do autor).

Segue-se que não podem ser nomeadas de serviço público atividades desempenhadas por particulares ou por pessoas de direito privado, ainda quando afetem relevantes interesses coletivos, se não foram reservadas pela Constituição da República ou por leis ordinárias ao Estado ou aos seus delegados.

Como referido, algumas atividades são exercidas sob o regime próprio do serviço público apenas quando "prestadas pelo Estado" (ex. saúde, educação, pesquisa científica, defesa do patrimônio ambiental). Exercidas por particulares, com ou sem fins lucrativos, não se sujeitam ao regime do serviço público, mas ao regime típico das pessoas privadas, o que muitas vezes lhes confere maior agilidade ou presteza no atendimento dos seus objetivos sociais.

\subsubsection{Organizações sociais e terceirização: o caso do Sistema Único de Saúde}

As organizações sociais também não se confundirão com entidades que prestam serviços para a administração segundo o regime que se 
convencionou denominar terceirização. A disciplina constitucional e legal do Sistema Único de Saúde(SUS) permite uma demonstração dessa afirmação.

Como se sabe, a Constituição brasileira assegura que a saúde é um direito de todos e um dever do Estado (art. 196). Ao prever tratar-se de um dever do Estado obriga o estatuto maior a que o Estado garanta o direito à saúde e não que ofereça diretamente e de forma exclusiva o atendimento a todos os brasileiros. Por isso, logo adiante, a lei fundamental enuncia que "são de relevância pública as ações e serviços de saúde, cabendo ao poder público dispor, nos termos da lei, sobre sua regulamentação, fiscalização e controle, devendo sua execução ser feita diretamente ou através de terceiros e, também, por pessoa física ou jurídica de direito privado" (art.197). A assistência à saúde é declarada expressamente atividade livre à iniciativa privada (art. 199, caput).

As ações e serviços públicos de saúde, integrados em termos nacionais, recebem a denominação de Sistema Único de Saúde (SUS). (art.198). No entanto, mesmo o Sistema Único de Saúde não repele a ação privada na execução de ações e serviços, prevendo, expressamente, a participação da iniciativa privada, em caráter complementar, com preferência para as entidades filantrópicas e as sem fins lucrativos (art. 199, $§ 1^{\circ}$, da Constituição; art. $4^{\circ}, \S 2^{\circ}$, da Lei n. 8.080, de 19 de setembro de 1990).

A participação da comunidade é também princípio expresso do Sistema Único de Saúde (art. 198 da Constituição; art. 7º, VIII, da Lei no 8.080, de 19 de setembro de 1990). Essa participação privada, porém, não pode dizer respeito às formas de parceria exercidas mediante concessão ou permissão de serviço público por duas razões já mencionadas. Em primeiro lugar, porque as ações e serviços de assistência à saúde são livres à iniciativa privada (art. 199, caput, da Constituição da República), não constituindo atividade exclusiva de Estado, passível de delegação executiva em sentido próprio. Em segundo lugar, porque a concessão e permissão de serviço incidem sobre atividades econômicas, onerosas, financiadas pelos próprios particulares-usuários mediante tarifas (art. 175 da Constituição). No sistema único de saúde, as ações e serviços não apresentam natureza econômica e são oferecidos de forma universal e gratuita.

Ora, a Constituição federal prevê que "as instituições privadas poderão participar de forma complementar do Sistema Único de Saúde, segundo diretrizes deste, mediante contrato de direito público ou convênio, tendo preferência as entidades filantrópicas e as sem fins lucrativos." (grifo nosso). Contrato e convênio são ambos acordos de vontades, distinguindo-se basicamente pela natureza dos interesses de ambas as partes. No contrato, os interesses são, de regra, antagônicos ou contraditórios; no convênio, os interesses são comuns ou convergentes. É evidente que a Constituição da República, na norma referida, pretendeu distinguir entre dois modos de prestação de serviços de saúde por particulares. No primeiro, 
mediante a referência ao instrumento do contrato, admite a terceirização, vale dizer, a contratação de particular-empresário, com vistas ao desempenho de atividades-meio na área de saúde financiada pelo Estado. Esta prestação de serviço, é certo, revestida de caráter empresarial e lucrativo, exige prévia licitação. No segundo modo, mediante a referência ao instrumento do convênio, admite a lei maior a colaboração de entidades sem fins lucrativos, com interesses coincidentes com a administração pública, não sendo cogitada remuneração pela gerência do serviço nem reciprocidade de obrigações e, portanto, de licitação (Di PIETRO, 1996: 109 e 117). Na hipótese de contrato, pelo caráter próprio da terceirização, não há prestação global do serviço de saúde, mas sim atuação em simples atividades operacionais ou ancilares (serviços de vigilância, manutenção, limpeza, transporte, seguro, etc.). Na hipótese de convênio, o que se pode estender também para a figura de acordo impropriamente denominada “contrato de gestão", não há impedimento à execução global do serviço pelo particular, pois trata-se de atividade livre à ação privada, fomentada ou financiada pelo Estado, mas não titularizada por ele. Pode-se, portanto, a partir da própria Constituição, apartar as duas figuras referidas, evitando mais uma espécie de incompreensão.

\section{Conclusão}

As organizações sociais representam uma nova estratégia de estimular parcerias de entidades privadas sem fins lucrativos com o Poder Público em serviços sociais livres à ação privada, fomentando a participação cidadã voluntária na esfera pública. Não podem ser superestimadas nem subestimadas como respostas conseqüentes à crise do aparelho do Estado no âmbito da prestação dos serviços sociais. O Estado com elas não se despede da responsabilidade de assegurar e garantir os direitos sociais básicos. O Estado continuará regulador e promotor de serviços sociais, contando, porém, com mecanismos de parceria renovados, ampliando a sua capacidade, direta ou indiretamente, de assegurar a fruição dos direitos sociais fundamentais.

As organizações sociais não consistirão em um novo tipo de pessoa jurídica, pois serão constituídas segundo as mesmas formas de constituição formal das tradicionais fundações ou associações sem fins lucrativos, mas representarão uma “inovação institucional”, porquanto desencadearão um marco legal amplamente inovador quanto ao modo de relacionamento entre o Estado e as instituições sem fins lucrativos de relevância social. Este marco legal, referido em detalhe no corpo do trabalho, vincula as organizações sociais a normas que, por um lado, estabelecem um regime de maiores restrições e maior vigilância do 
Estado se comparado ao atual regime jurídico aplicável às tradicionais entidades privadas de utilidade pública e, por outro, assegura-lhes também maiores benefícios e vantagens. Esse fato revela que a denominação organização social é uma expressão elíptica. Denominam-se sinteticamente organizações sociais as entidades privadas, fundações ou associações sem fins lucrativos, que usufruem do título de organização social. Este título é conferido por um ato formal de reconhecimento do Poder Público, semelhante em muitos aspectos à qualificação deferida às instituições privadas sem fins lucrativos quando recebem o título de utilidade pública.

As organizações sociais contribuirão ainda para o preenchimento de uma grave lacuna da legislação referente à concessão de títulos de utilidade pública, pois permitirão pela primeira vez uma diferenciação nítida entre entidades sem fins lucrativos dirigidas ao atendimento de demandas sociais de forma comunitária e impessoal e entidades de favorecimento mútuo (clubes, agremiações), sem fins lucrativos também, mas orientadas ao oferecimento de vantagens ou benefícios exclusivos a grupos delimitados de sócios ou clientes.

A polêmica suscitada com o modelo das organizações sociais produziu uma série de conceitos equívocos e mal fundamentados sobre a própria natureza jurídica das entidades qualificadas. Esta identificação equívoca das organizações sociais pode produzir danos irreversíveis ao modelo, pois dela depende o reconhecimento do próprio regime jurídico a que se submeterão essas entidades. O texto tenta demonstrar o erro de confundir, por um lado, as organizações sociais com os entes da administração indireta do Estado e, por outro, com mecanismos de privatização ou terceirização de serviços públicos. Neste esforço de clarificação foram tratados temas diversos, como a distinção entre serviços privados de interesse público e serviços públicos, bem como referidas diversas normas constitucionais brasileiras, relacionadas ao tema da parceria do Estado com as entidades sem fins lucrativos. Em todos esses temas, porém, os juristas são convocados a interferir como protagonistas, co-participando da tarefa de construção de uma nova mentalidade administrativa. Espera-se que doravante com alguma maior simpatia; pois, como enuncia PONTES DE MIRANDA, em trecho citado neste trabalho, "com a antipatia não se interpreta, —ataca-se". 


\title{
Projeto de lei no ${ }^{\circ}$, de de de 1997.
}

Dispõe sobre a qualificação de entidades como organizações sociais, a criação do Programa Nacional de Publicização e dá outras providências.

O Congresso Nacional decreta:

\author{
Capítulo I \\ Das Organizações Sociais \\ Seção I \\ Da Qualificação
}

Art. 1ํ O Poder Executivo poderá qualificar como organizações sociais pessoas jurídicas de direito privado, sem fins lucrativos, cujas atividades sejam dirigidas ao ensino, à pesquisa científica e ao desenvolvimento tecnológico, à proteção e preservação do meio ambiente, à cultura e à saúde, atendidos os requisitos previstos nesta Lei.

Art. $2^{\circ}$ São requisitos específicos para que as entidades privadas referidas no artigo anterior habilitem-se à qualificação como organização social:

I - comprovar o registro de seu ato constitutivo, dispondo sobre:

a) natureza social de seus objetivos relativos à respectiva área de atuação;

b) finalidade não-lucrativa, com a obrigatoriedade de investimento de seus excedentes financeiros no desenvolvimento das próprias atividades;

c) previsão expressa da entidade ter, como órgãos de deliberação superior e de direção, um Conselho de Administração e uma Diretoria, definida nos termos do Estatuto, assegurado àquele composição e atribuições normativas e de controle básicas previstas nesta Lei;

d) previsão de participação, no órgão colegiado de deliberação superior, de representantes do Poder Público e de membros da comunidade, de notória capacidade profissional e idoneidade moral;

e) composição e atribuições da Diretoria da entidade;

f) obrigatoriedade de publicação anual, no Diário Oficial da União, dos relatórios financeiros e do relatório de execução do contrato de gestão;

g) em caso de associação civil, a aceitação de novos associados, na forma do estatuto;

h) proibição de distribuição de bens ou de parcela do patrimônio líquido em qualquer hipótese, inclusive em razão de desligamento, retirada ou falecimento de associado ou membro da entidade; 
i) previsão de incorporação integral do patrimônio, dos legados ou das doações que lhe foram destinados, bem como dos excedentes financeiros decorrentes de suas atividades, em caso de extinção ou desqualificação da entidade, ao patrimônio de outra organização social qualificada no âmbito da União, da mesma área de atuação, ou ao patrimônio da União, dos Estados, do Distrito Federal ou dos Municípios, na proporção dos recursos e bens por estes alocados;

II - ter a entidade recebido aprovação em parecer favorável, quanto à conveniência e oportunidade de sua qualificação como organização social, do Ministro ou Titular de órgão supervisor ou regulador da área de atividade correspondente ao seu objeto social e do Ministro da Administração Federal e Reforma do Estado.

\section{Seção II \\ Do Conselho de Administração}

Art. 3o O Conselho de Administração deve estar estruturado nos termos que dispuser o respectivo estatuto, observados, para os fins de atendimento dos requisitos de qualificação, os seguintes critérios básicos de composição e funcionamento:

I - ser composto por:

a) vinte a quarenta por cento de membros natos representantes do Poder Público, definidos pelo estatuto da entidade;

b) vinte a trinta por cento de membros natos representantes de entidades da sociedade civil, definidos pelo estatuto;

c) até dez por cento, no caso de associação civil, de membros eleitos dentre os membros ou os associados;

d) dez a trinta por cento de membros eleitos pelos demais integrantes do Conselho, dentre pessoas de notória capacidade profissional e reconhecida idoneidade moral;

e) até dez por cento de membros indicados ou eleitos na forma estabelecida pelo estatuto;

II - os membros eleitos ou indicados para compor o Conselho devem ter mandato de quatro anos, admitida uma recondução;

III - os representantes de entidades previstos nas alíneas "a" e "b" deverão compor mais de cinqüenta por cento do Conselho;

IV - o primeiro mandato de metade dos membros eleitos ou indicados deve ser de dois anos, segundo critérios estabelecidos no estatuto;

$\mathrm{V}$ - o dirigente máximo da entidade deve participar das reuniões do Conselho, sem direito a voto;

VI - o Conselho deve reunir-se ordinariamente, no mínimo, três vezes a cada ano, e extraordinariamente, a qualquer tempo;

VII - os conselheiros não receberão remuneração pelos serviços que, nesta condição, prestarem à organização social, ressalvada a ajuda de custo por reunião da qual participe o conselheiro;

VIII - os conselheiros eleitos ou indicados para integrar a Diretoria da entidade devem renunciar ao assumirem as correspondentes funções executivas.

Art. 4ํㅜㄹa Par fins de atendimento dos requisitos de qualificação, devem estar inclusas entre as atribuições privativas do Conselho de Administração: 
I - fixar o âmbito de atuação da entidade, para consecução do seu objeto; timentos;

III - aprovar a proposta de orçamento da entidade e o programa de inves-

IV - designar e dispensar os membros da Diretoria;

V - fixar a remuneração dos membros da Diretoria;

VI - aprovar e dispor sobre a alteração dos estatutos e a extinção da entidade por maioria, no mínimo, de dois terços de seus membros;

VII - aprovar o regimento interno da entidade, que deve dispor, no mínimo, sobre a estrutura, o gerenciamento, os cargos e as competências;

VIII - aprovar, por maioria, no mínimo de dois terços de seus membros, o regulamento próprio, contendo os procedimentos que deve adotar para a contratação de obras e serviços, bem como para compras e alienações, e o plano de cargos, salários e benefícios dos empregados da entidade;

IX - aprovar e encaminhar ao órgão supervisor da execução do contrato de gestão, os relatórios gerenciais e de atividades da entidade, elaborados pela Diretoria;

$\mathrm{X}$ - fiscalizar o cumprimento das diretrizes e metas definidas e aprovar os demonstrativos financeiros e contábeis e as contas anuais da entidade, com o auxílio de auditoria externa.

\section{Seção III \\ Do Contrato de Gestão}

Art. 5o Para os efeitos desta Lei, entende-se por contrato de gestão o instrumento firmado entre o Poder Público e a entidade qualificada como organização social, com vistas à formação de uma parceria entre as partes para fomento e execução de atividades relativas as áreas relacionadas no art. 1으.

Art. 6º $\mathrm{O}$ contrato de gestão, elaborado de comum acordo entre o órgão supervisor e a organização social, discriminará as atribuições, responsabilidades e obrigações do Poder Público e da organização social no desempenho das ações a cargo desta.

Parágrafo único. O contrato de gestão deve ser submetido, após aprovação pelo Conselho de Administração da entidade, ao Ministro de Estado ou autoridade supervisora ou reguladora da área correspondente à atividade fomentada.

Art. $7^{o} \mathrm{Na}$ elaboração do contrato de gestão devem ser observados os princípios da legalidade, impessoalidade, moralidade, publicidade, economicidade e, também, os seguintes preceitos:

I - constar a especificação do programa de trabalho proposto pela organização social, a estipulação das metas a serem atingidas e os respectivos prazos de execução, bem como previsão expressa dos critérios objetivos de avaliação de desempenho a serem utilizados, mediante indicadores de qualidade e produtividade;

II - a estipulação dos limites e critérios para a despesa com a remuneração e vantagens de qualquer natureza a serem percebidas pelos dirigentes e empregados das organizações sociais, no exercício de suas funções.

Parágrafo único. Os ministros de Estado ou autoridades supervisoras, observadas as peculiaridades de suas áreas de atuação, devem definir as demais cláusulas necessárias dos contratos de gestão de que sejam signatários. 


\section{Seção IV \\ Da Execução e Fiscalização do Contrato de Gestão}

Art. $8^{\circ}$ A execução do contrato de gestão celebrado por organização social será fiscalizada pelo Ministério da área correspondente, permitida a delegação ao órgão da Administração diretamente vinculado à atividade desenvolvida.

$\S 1$ ○ O contrato de gestão deve permitir ao Poder Público requerer a apresentação pela entidade qualificada, ao término de cada exercício ou a qualquer momento, conforme recomende o interesse público, de relatório pertinente à execução do contrato de gestão, contendo comparativo específico das metas propostas com os resultados alcançados, acompanhado da prestação de contas correspondente ao exercício financeiro.

$\S 2$ O Os resultados atingidos com a execução do contrato de gestão serão analisados, periodicamente, por comissão de avaliação, indicada pelo Ministro de Estado ou pelo titular mencionados no caput deste artigo, composta por especialistas de notória qualificação, que emitirão relatório conclusivo, a ser encaminhado ao instituidor da comissão, ao órgão de governo responsável pela supervisão ou regulação da atividade e aos órgãos de controle interno e externo da União.

Art. 9o Os responsáveis pela fiscalização da execução do contrato de gestão, ao tomarem conhecimento de qualquer irregularidade ou ilegalidade na utilização de recursos ou bens de origem pública por organização social, dela darão ciência ao Tribunal de Contas da União, sob pena de responsabilidade solidária.

Art. 10. Sem prejuízo da medida a que alude o artigo anterior, quando assim o exigir a gravidade dos fatos ou o interesse público, havendo indícios fundados de malversação de bens ou recursos de origem pública, os responsáveis pela fiscalização representarão ao Ministério Público ou à Procuradoria do órgão para que requeira ao juízo competente a decretação da indisponibilidade dos bens da entidade e o seqüestro dos bens dos seus dirigentes, bem como de agente público ou terceiro, que possam ter enriquecido ilicitamente ou causado dano ao patrimônio público.

$\S 1$ 응 $\mathrm{O}$ pedido de seqüestro será processado de acordo com o disposto nos arts. 822 e 825 do Código de Processo Civil.

$\S 2$ o Quando for o caso, o pedido incluirá a investigação, o exame e o bloqueio de bens, contas bancárias e aplicações mantidas pelo demandado no exterior, nos termos da lei e dos tratados internacionais.

$\S$ 3o Até o término da ação, o Poder Público permanecerá como depositário e gestor dos bens e valores seqüestrados ou indisponíveis e velará pela continuidade das atividades sociais da entidade.

\section{Seção V \\ Do Fomento às Atividades Sociais}

Art. 11. As entidades qualificadas como organizações sociais ficam declaradas como entidades de interesse social e utilidade pública para todos os efeitos legais, inclusive tributários.

Art. 12. Às organizações sociais poderão ser destinados recursos orçamentários e bens públicos necessários ao cumprimento do contrato de gestão.

$\S 1$ 을 Ficam assegurados às organizações sociais os créditos previstos no orçamento e as respectivas liberações financeiras, de acordo com o cronograma de desembolso previsto no contrato de gestão. 
$\S 2$ Poderá ser adicionada aos créditos orçamentários destinados ao custeio do contrato de gestão parcela de recursos para compensar desligamento de servidor cedido desde que haja justificativa expressa da necessidade pela organização social.

$\S 3$ 3ㅇs bens de que trata este artigo serão destinados às organizações sociais, dispensada licitação, mediante permissão de uso, consoante cláusula expressa do contrato de gestão.

Art. 13. Os bens móveis públicos permitidos para uso poderão ser substituídos por outros de igual ou maior valor, condicionado a que os novos bens integrem o patrimônio da União.

Parágrafo único. A permuta de que trata o caput deste artigo dependerá de prévia avaliação do bem e expressa autorização do Poder Público.

Art. 14. Fica facultado ao Poder Executivo a cessão especial de servidor para as organizações sociais, com ônus para a origem.

$\S 1^{\circ}$ Não será incorporada aos vencimentos ou à remuneração de origem do servidor cedido qualquer vantagem pecuniária que vier a ser paga pela organização social.

$\S 2$ Não será permitido o pagamento de vantagem pecuniária permanente por organização social a servidor cedido com recursos provenientes do contrato de gestão, ressalvada a hipótese de adicional relativo ao exercício de função temporária de direção e assessoria.

Art. 15. A Administração Pública Federal direta, autárquica e fundacional fica dispensada de processos licitatórios para celebração de contratos de prestação de serviços com as organizações sociais, qualificadas no âmbito da União, para atividades contempladas no objeto do contrato de gestão.

Art. 16. São extensíveis, no âmbito da União, os efeitos dos arts. $11,12, \S 3^{\circ} \mathrm{e}$ 15, para as entidades qualificadas como organizações sociais pelos Estados, Distrito Federal e Municípios, quando houver reciprocidade e desde que a legislação local não contrarie os preceitos desta Lei e a legislação específica de âmbito federal.

\section{Seção VI \\ Da Desqualificação}

Art. 17. O Poder Executivo poderá proceder a desqualificação da entidade como organização social quando constatado o descumprimento das disposições contidas no contrato de gestão.

$\S 1$ o A desqualificação será precedida de processo administrativo, assegurado o direito de ampla defesa, respondendo os dirigentes da organização social, individual e solidariamente, pelos danos ou prejuízos decorrentes de sua ação ou omissão.

$\S 2^{\mathrm{o}}$ A desqualificação importará reversão dos bens permitidos e dos valores entregues à utilização da organização social, sem prejuízo de outras sanções cabíveis.

\section{Capítulo II \\ Das Disposições finais e transitórias}

Art. 18. A organização social fará publicar, no prazo máximo de noventa dias contados da assinatura do contrato de gestão, regulamento próprio contendo os procedimentos que adotará para a contratação de obras e serviços, bem como para compras com emprego de recursos provenientes do Poder Público. 
Art. 19. A organização social que absorver atividades de entidade federal extinta no âmbito da área de saúde deverá considerar no contrato de gestão, quanto ao atendimento da comunidade, os princípios do Sistema Único da Saúde, expressos no art. 198 da Constituição Federal e no art. 7º da Lei nº 8.080, de 19 de setembro de 1990.

Art. 20. Será criado, mediante decreto do Poder Executivo, o Programa Nacional de Publicização - PNP, com o objetivo de estabelecer diretrizes e critérios para a qualificação de organizações sociais, a fim de assegurar a absorção de atividades desenvolvidas por entidades ou órgãos públicos da União, que atuem nas atividades referidas no art. $1^{\underline{o}}$, por organizações sociais, qualificadas na forma desta Lei, observado os seguintes princípios:

I - ênfase no atendimento do cidadão-cliente;

II - ênfase nos resultados, qualitativos e quantitativos nos prazos pactuados;

III - controle social das ações de forma transparente.

Art. 21. A extinção de órgãos públicos federais e a absorção de suas atividades e serviços por organizações sociais, qualificadas na forma desta Lei, observarão os seguintes preceitos:

I - os servidores integrantes dos quadros da entidade e dos órgãos públicos cujas atividades forem absorvidas pelas organizações sociais, terão garantidos todos os direitos decorrentes do respectivo regime jurídico e integrarão quadro em extinção do Ministério correspondente ou do Ministério da Administração Federal e Reforma do Estado, quando não existir vinculação direta a Ministério, sendo facultada à Administração a cessão do servidor para a organização social, em caráter irrecusável para aquele, com ônus para a origem;

II - a desativação da entidade e dos órgãos será realizada mediante inventário simplificado de seus bens imóveis e de seu acervo físico, documental e material, bem como dos contratos e convênios; com a adoção de providências dirigidas à manutenção e ao prosseguimento das atividades sociais a cargo do órgão ou entidade em extinção, com sub-rogação na organização social, nos termos da legislação aplicável em cada caso;

III - os recursos e as receitas orçamentárias de qualquer natureza, destinados aos órgãos e à entidade a que se refere o artigo anterior, serão utilizados no processo de extinção e para a manutenção e o financiamento das atividades sociais durante o inventário simplificado, devendo parcela deste ser reprogramada, mediante crédito especial a ser enviado ao Congresso Nacional no prazo de 15 dias, para os órgãos ou entidades supervisoras dos contratos de gestão a serem firmados com as organizações sociais que houverem absorvido as atividades, para o fomento destas, assegurada a liberação periódica do respectivo desembolso financeiro em seu favor, nos termos dos contratos de gestão;

IV - encerrados os processos de inventário simplificado, os cargos efetivos vagos e os em comissão serão considerados extintos;

V - a organização social, que tiver absorvido as atribuições da entidade ou órgão extinto, poderá adotar os símbolos designativos destes, seguidos da identificação "OS".

$\S 11^{\circ}$ Serão instaurados, com a supervisão do Ministério da Administração Federal e Reforma do Estado, processos de inventário simplificado, a cargo dos Ministérios ou do órgão a que estavam vinculados os órgãos e a entidade extinta. 
$\S 2$ 2 A absorção pelas organizações sociais das atividades dos órgãos ou entidade extintos efetivar-se-á mediante a celebração de contrato de gestão, na forma dos arts. $6^{\circ}$ e $7^{\circ}$ desta Lei.

§ 3o Poderá ser adicionada às dotações orçamentárias referidas no III deste artigo, parcela dos recursos decorrentes da economia de despesa incorrida pela União com os cargos e funções comissionados existentes na entidade ou nos órgãos extintos.

Art. 22. Esta Lei entra em vigor na data de sua publicação.

Brasília, de de 1997; 175ํ da Independência e 108oa República. 
1 Texto apresentado no II Congresso Interamericano sobre a Reforma do Estado e da Administração Pública promovido pelo CLAD - Centro Latinoamericano de Administración para el Desarrollo, realizado na Ilha de Margarita, Venezuela, em outubro de 1997. Um esboço preliminar do texto foi preparado para uma reunião de trabalho com a Assessoria Jurídica da Casa Civil da Presidência da República em 01/02/96.

2 A administração é pública. Não é somente executiva nem unicamente estatal, mas é mais do que estatal. A administração pública é o gênero, e o estatal é uma das espécies. O público não está somente nas mãos do Estado. O Estado não é o único dono e soberano do público, à medida que na "administração do público" devem participar, também, os corpos intermediários que compreendem as corporações profissionais, os sindicatos, os consórcios públicos, as cooperativas públicas, os concessionários de serviços públicos, as universidades privadas e outros modelos organizacionais que a sociedade cria, em função do pluralismo social, para que detenham a defesa do interesse de alguns que, junto aos demais, é o interesse de todos."

3 "Não se pode pretender que o Estado monopolize a atenção de todas as necessidades coletivas. O crescimento quantitativo e qualitativo das necessidades, próprio da complexidade da vida moderna, requer uma participação mais ativa dos corpos intermediários no campo das atividades próprias da Administração Pública (...) A democracia, como forma civilizada de viver, aspira à plena realização do homem em liberdade, para tanto exige uma "participação integral", não só política, nem política simplesmente eleitoral, mas também administrativa, econômica e social. O homem deve ser "partícipe" da gestão pública em seus distintos níveis institucionais." (1995:85) 


\section{Referências bibliográficas}

Bandeira de Mello, Celso Antônio. Curso de direito administrativo, $7^{\mathrm{a}}$ ed., São Paulo, Ed. Malheiros, 1995.

Boвbio, Norberto. Estado, governo, sociedade: para uma teoria geral da política. Trad. de Marco Aurélio Nogueira, Rio de Janeiro, Ed. Paz e Terra, 1987.

BResser Pereira, Luiz Carlos. Crise econômica e reforma do Estado no Brasil: para uma nova interpretação da América Latina. Trad. de Ricardo Ribeiro e Martha Jalkauska, São Paulo, Ed. 34, 1996.

. "A reforma do Estado nos anos 90: lógica e mecanismos de controle".

In: Cadernos MARE de Reforma do Estado, n. 1, Brasília, Ministério da Administração Federal e Reforma do Estado, 1997.

Cassagne, Juan Carlos. La intervención administrativa, 4. ed., Buenos Aires, AbeledoPerrot, 1994.

Cunill Grau, Nuria. "A rearticulação das relações Estado-sociedade: em busca de novos significados”. In: Revista do Serviço Público, ano 47, vol. 120, n. 1, jan-abr., 1996.

Di PIEtro, Maria Sylvia Zanella. Parcerias na Administração Pública. São Paulo, Ed. Atlas, 1996.

Dromi, Roberto. Reforma del Estado y privatizaciones. Tomo I. Buenos Aires, Editorial Astrea, 1991.

gentina, 1995.

EnTERRÍA. Eduardo García e Fernándes, Tomás-Ramón. Curso de Derecho Administativo, Tomo II, $2^{\circ}$ ed., Madrid, Editorial Civitas, 1989.

FerRaz JR., Tércio Sampaio. Função Social da Dogmática Jurídica. São Paulo, Ed. Revista dos Tribunais, 1980.

. Introdução ao Estudo do Direito: técnica, decisão, dominação. 2. ed. São Paulo, Atlas, 1994.

FerReIRA, Sérgio de Andréa. Lições de Direito Administrativo. Rio de Janeiro, Ed. Rio, 1972.

Miranda, Pontes de. Comentários à Constituição de 1967, com a Emenda n. 1 de 1969, Tomo I, Rio de Janeiro, Ed. Forense, 1987.

Moreira Neto, Diogo de Figueiredo. Curso de Direito Administrativo, $8^{\text {a }}$ ed., Rio de Janeiro, Ed. Forense, 1989.

Oliveira, Anna Cyntia. Construindo um Marco Regulatório para a Consolidação do Setor Privado não Lucrativo e de Fins Públicos no Brasil. Estudo elaborado a pedido do Conselho Comunidade Solidária, Brasília, original mimeografado, nov. 1996.

Palazzo, José Luis, Sesín, Domingo Juan e Lembeye, Víctor Armando Rolón. La Transformación del Estado. Buenos Aires, Ediciones Depalma, 1992.

Pereira JR., Jessé Torres. "A utilidade pública de associações privadas e das fundações de menores”. In: Arquivos do Ministério da Justiça, Ano XXX, junho, 1973, n. 126. 
Reforma administrativa e marco legal das organizações sociais no Brasil: as dúvidas dos juristas sobre o modelo das organizações sociais

\section{Paulo Eduardo Garrido Modesto}

O modelo brasileiro das organizações sociais representa uma das respostas possíveis à crise do aparelho do Estado no âmbito da prestação dos serviços sociais. Essas entidades são percebidas como uma forma de parceria do Estado com as instituições privadas de fins públicos (perspectiva ex parte principe) ou, sob outro ângulo, uma forma de participação popular na gestão administrativa (perspectiva ex parte populi). No texto são tematizadas as diferenças e semelhanças entre o marco legal das organizações sociais e das entidades de utilidade pública no Brasil, as notas distintivas entre a disciplina dos serviços privados de interesse público e dos serviços públicos, bem como o que distingue juridicamente o modelo das organizações sociais de processos de privatização e terceirização. Em todos esses temas os juristas aparecem como protagonistas na determinação dos limites do modelo das organizações sociais, evidenciando que processos de reforma normativa exigem, para serem eficazes, uma concomitante reforma na mentalidade dos agentes públicos.

Reforma administrativa y marco legal de las organizaciones sociales en Brasil: Las duds de los juristas sobre el modelo de las organizaciones sociales

\section{Paulo Eduardo Garrido Modesto}

El modelo brasileño de las organizaciones sociales representa una de las respuestas posibles para la crisis del aparato del Estado en el ámbito de la prestación de servicios sociales. Las entidades son compreendidas como una forma de parcería del Estado com las instituciones privadas de fines públicos (perspectiva ex parte principe) o, bajo otro ángulo, una forma de participación popular en la gestión administrativa (perspectiva ex parte populi). El texto tiene como temas las diferencias y similitudes entre el marco legal de las organizaciones sociales y de las entidades de utilidad pública en Brasil, las notas distintivas entre la disciplina de los servicios de interés y de los servicios públicos, así como lo que diferencia juridicamente el modelo de las organizaciones sociales de los procesos de privatización y tercerización. En todos estos temas los juristas aparecen como protagonistas en la determinación de los límites del modelo de las organizaciones sociales, y evidencian que los procesos de reforma normativa exigen, para lograr eficacia, una concomitante reforma en la mentalidad de los agentes públicos.

Administrative reform and the legal framework of social organizations in Brazil: jurists uncertainties about the model of social organizations

\section{Paulo Eduardo Garrido Modesto}

The brazilian model of social organizations represents one out of many possible responses to the State crisis in which refers to the delivery of social services. These bodies are perceived as a form of partnership between the State and private institutions for public interest (an ex parte principe perspective) or, from a different point of view, 
a form of popular participation in the administrative management (ex parte populi perspective). The text stresses the differences and similarities between the legal framework of social organizations and the public interest entities in Brazil, the distinctive notes between the discipline of private services of public interest and that of public services, while making a juridical distinction between the model of social organizations of privatization processes and the purchase of services. All these issues have jurists as protagonists in the setting of limits to the social organization model, as an indication that any process of normative reform wil demand, for effectiveness' sake, a concurrent reform of public agents' minds. 